\title{
RECENT LOCAL GEODYNAMIC PROCESSES IN THE PENOLA STRAIT - LEMAIRE CHANNEL FAULT AREA (WEST ANTARCTICA)
}

\author{
Ihor SAVCHYN *, Korneliy TRETYAK, Volodymyr HLOTOV, Yevhenii SHYLO, \\ Ihor BUBNIAK, Iurii GOLUBINKA and Volodymyr NIKULISHYN
}

Lviv Polytechnic National University, Institute of Geodesy, Karpinski Street 6, Lviv, Ukraine, 79013

*Corresponding author's e-mail: ih.savchyn@gmail.com

\begin{tabular}{l} 
ARTICLE INFO \\
\hline Article history: \\
Received 29 January 2021 \\
Accepted 16 April 2021 \\
Available online 27 April 2021 \\
\hline
\end{tabular}

Keywords:

Recent geodynamic processes

Static GNSS survey

Geodynamic polygon

Geological structure

Kinematic model

\begin{abstract}
We present the crustal deformation field in the Penola Strait - Lemaire Channel fault area (West Antarctica), based on the analysis of the 5 seasonal cycles of static GNSS survey. This 5 GNSS campaigns were conducted with approximately a 16-year interval from 2003 to 2019. The analyses indicate that average linear velocities of horizontal movements are multidirectional but no larger than $1-2 \mathrm{~mm} / \mathrm{yr}$. Average linear velocities of vertical movements are no larger than $\pm 3 \mathrm{~mm} / \mathrm{yr}$. In the present work scheme of vertical and horizontal movements has been drawn out. The obtained results correlate well with the movements of the surrounding GNSS stations. Based on the analysis of spatial distribution of the Earth's surface dilatation velocity the zones of extreme compression and expansion values were revealed. The analyses of spatial distribution of the Earth's surface total shear velocity indicate that the studied region is horizontally heterogeneous. Based on the analysis of obtained results, a new kinematic model of fault area was developed. The possibility of using static GNSS survey to study recent local geodynamic processes in Antarctica has been demonstrated.
\end{abstract}

\section{INTRODUCTION}

The geological and tectonic structures of the Antarctic continent, as well as the current global, regional and local geodynamic processes that occur on it, are the least studied in comparison with other continents. The main reasons are the great remoteness, the inaccessibility and the almost complete coverage of the Antarctic continent with powerful ice systems. Recently, the results of GNSS observation have been frequently used for studies of geodynamic processes. Zanutta et al. (2018) noted that in geosciences, GNSS and gravimetric observations are key methods to highlight geodynamic and geophysical phenomena of a geological region, and are a fundamental support in the formulation of deformation models at regional and continental scale, referring also to the interaction mechanisms of interaction between the solid Earth and the cryosphere. For instance, by Richter et al. (2008, 2013) the velocity magnitudes and azimuths of the ice flow at 50 surface markers in the Vostok Subglacial Lake region (East Antarctica) have been determined from repeated GNSS observations. As a result, the flow velocities do not exceed $2 \mathrm{~m} / \mathrm{yr}$. The flow direction diverges south east in the southern part and east north in the northern part of the subglacial lake. Zanutta et al. $(2017,2018)$ based on GNSS data collected over the past 20 years determined recent geodynamic parameters of Victoria Land (East Antarctica). Processing highlights a movement of
Victoria Land towards the south east with a pathway nearly parallel to the transforms, which start from the Tasman and Balleny fracture zones and propagate on land in Antarctica. Particular attention is paid to recent geodynamic processes in West Antarctica, which covers in the past tectonically active zone as well as the area with recent volcanic manifestations. Dietrich et al. (2004), Jiang et al. (2009) and Berrocoso et al. (2016) used GNSS observation to monitor the geodynamic processes of the region defined by the South Shetland Islands archipelago, the Bransfield Basin and the Antarctic Peninsula (all in West Antarctica) which is characterized by highly complex and unique geotectonic surroundings. The authors found that the absolute horizontal velocity vectors have a north east direction and are in the range of 15$25 \mathrm{~mm}$. However, Berrocoso et al. (2016) inferred absolute vertical velocity vectors indicate subsidence in the north-eastern part of the South Shetland Islands archipelago in contrast to the uplift movement observed by Dietrich et al. (2004), but in agreement with the data published by Jiang et al. (2009) and Bevis et al. (2009). In Rosado et al. (2019) GNSS observation on 15 stations were used in the island's tectonic and volcanic rocks behaviour on Deception Island (West Antarctica). The obtained results demonstrate that Deception and Livingston Islands have a similar behaviour derived from the Bransfield Basin extension and the Phoenix micro-plate 


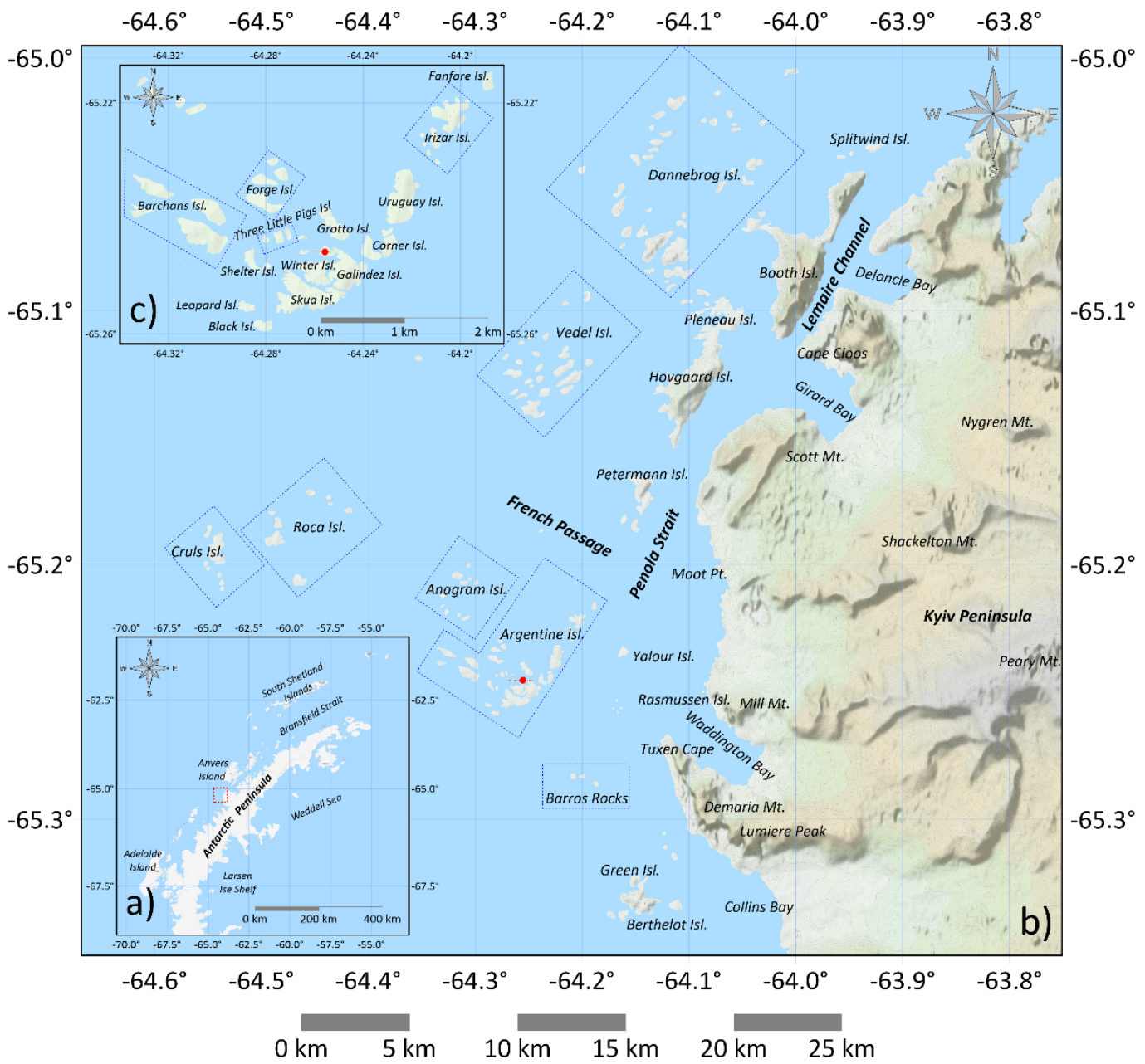

Fig. 1 Index map of the Penola Strait - Lemaire Channel fault area

a) Antarctic Peninsula, b) Penola Strait - Lemaire Channel fault area, c) Argentine Islands archipelago (….... - group of islands, $\bullet$ - Antarctic Station "Academic Vernadsky")

subsidence processes. However, Deception Island is also highly influenced by its volcanic activity. Deception Island's volcanic behaviour between 1991 and 2018 is shown by the velocity field, strain tensors and pressure source evolution obtained from the ground-displacements at the geodetic benchmarks. The Antarctic continent is largely devoid of man-made factors and is, therefore, a unique testing ground for recent geodynamic processes. The conducted analysis confirms that GNSS observation considerably supplement and introduce new information about recent geodynamic processes. However, despite the significant development of GNSS networks in the Antarctic continent, there are a large number of areas in need of research. One of them is the Penola Strait - Lemaire Channel fault area (West Antarctica). According to Bakhmutov (1998), the area along Penola Strait consists of two parts: the synclinical zone (Antarctic Peninsula) and anticlinal zone (Argentine Islands archipelago). Between the two zones, Curtis (1966) based on the results of geological and paleomagnetic studies, predicted the occurrence of a rupturing fault, which coincides with the direction of the fairway part of Penola Strait and Lemaire Channel (Fig. 1) also, it is testified by Geological map of the Southern Graham Land (1981).

Penola Strait $\left(65^{\circ} 11^{\prime} 35^{\prime \prime} \mathrm{S}, 64^{\circ} 7^{\prime} 38^{\prime \prime} \mathrm{W}\right)$ is a strait $20 \mathrm{~km}$ long and averaging $3.7 \mathrm{~km}$ wide, separating the Argentine Islands archipelago, Petermann Island and Hovgaard Island from the west coast of Graham Land. Lemaire Channel $\left(65^{\circ} 04^{\prime} 54^{\prime \prime} \mathrm{S}, 63^{\circ} 57^{\prime} 24^{\prime \prime} \mathrm{W}\right)$ is a strait $11 \mathrm{~km}$ long and just $1.6 \mathrm{~km}$ wide at its narrowest point, separating the Kyiv Peninsula in the mainland's Graham Land and Booth Island. Ryan (2007) noted that Penola Strait - Lemaire Channel fault to be the product of a major fault that is mapped as continuing through the Bismarck Strait and cropping out again on Wiencke Island just off the south-east coast of Anvers Island.

The immediate proximity of this area to the Ukrainian Antarctic Station "Academic Vernadsky" $\left(65^{\circ} 14^{\prime} 44^{\prime \prime} \mathrm{S}, 64^{\circ} 15^{\prime} 28^{\prime \prime} \mathrm{W}\right)$ has contributed to a large of different geological, geomorphological and geophysical studies of the region. For example, Bakhmutov (1998, 2006) and Maksymchuk et al. (2002) based on the results of instrumental 
tectomagnetic and geological studies, it is assumed that tectonic activity is present in the Three Little Pigs Islands. Maksymchuk et al. (2009) also note that the most intensive tectonomagnetic anomalies were defined on the Three Little Pigs Islands. The high amplitude of the tectonomagnetic effect is caused by the high magnetization of rocks and the intensive tectonic strains in the crust. The authors conclude that there is a submedian tectonic fault near the Ukrainian Antarctic Station "Academic Vernadsky" and active tectonic processes occur within its boundaries. Rusov et al. (2014) based on magnetic field strength and radon concentrations measured along a tectonomagnetic profile in the surroundings of the Ukrainian Antarctic Station "Academic Vernadsky" showed a positive correlation between the annual surface radon concentration and annual changes of magnetic field relative to a base epoch GNSS stations, and also the good coincidence with theoretical calculation. Such an approach permits to reveal the deformation accumulation in this region which will probably discharge by the slow relaxation mechanisms. In Kylchitskiy et al. (2010), based on the results of GNSS observation and geological-geophysical data, a geodynamic model of the lithosphere was developed in the region of the Ukrainian Antarctic Station "Academic Vernadsky". As a result of detailed analysis of static GNSS observation in Kylchitskiy et al. (2010) and Tretyak et al. (2016), the presence of horizontal movements in the region of Roca Islands, Galindez Island, Fanfare Island and Petermann Island, as well as elevations in the region of Barchans Islands was identified. According to the authors, such processes are related to the compression and rotation of the Antarctic lithosphere plate clockwise. As a part of the seasonal 24th Ukrainian Antarctic Expedition (January-April 2019), a GNSS station ASAV $\left(65^{\circ} 14^{\prime} 44^{\prime \prime} \mathrm{S}, 64^{\circ} 15^{\prime} 26^{\prime \prime} \mathrm{W}\right)$ was installed and put into operation near the Ukrainian Antarctic Station "Academic Vernadsky" which should be the first step to develop a permanent GNSS monitoring network in the Penola Strait - Lemaire Channel fault area.

The analysis of the results of complex geophysical, geological and geomorphological studies shows the presence of active recent local geodynamic processes in the Penola Strait - Lemaire Channel fault area. In this regard, there was a need to create a geodynamic polygon for the Penola Strait - Lemaire Channel fault area monitoring, as well as to conduct repeated GNSS observations to differentiate recent local geodynamic processes and establish correlation and mathematical relationships between kinematics and tectonic structure in the fault.

\section{GEOLOGICAL SETTING}

The Penola Strait - Lemaire Channel fault area is near the Antarctic Peninsula, which belongs to the Antarctic Plate. The recent geodynamics and seismicity of the Antarctic Peninsula are determined by the dynamics and kinematics of the Antarctic Plate, the Scotia Plate and the South American Plate.
Nowadays there are three opinions on the geodynamic processes of subduction in the Antarctic Peninsula: a) subduction has completed about $4 \mathrm{Ma}$ (Barker, 1982), b) subduction is ongoing (Pelayo and Wiens, 1989; Robertson et al., 2003b and c) a slab-rollback occurs after a subduction of approximately $3.3 \mathrm{Ma}$ (Gracia et al., 1996; Galindo-Zaldivar et al., 1996, 2004). These processes led to the opening of the Bransfield Strait (Pelayo and Wiens, 1989; Larter and Barker, 1991; Galindo-Zaldivar et al., 1996, 2004).

Tectonically the Penola Strait - Lemaire Channel fault area is located on the border of the Eastern and Central Domains of Antarctic Plate, which is composed of intrusive and effusive rocks. Domains are separated by a series of faults, mainly identified by geophysical studies and represented by different kinematic types. According to Vaughan and Storey (2000) and Ferraccioli et al. (2006), the domains were accreted and sutured along the outskirts of Gondwana in the middle Cretaceous. Yegorova et al. (2011) noted that the major tectonic structures of the region are expressed on maps of the seafloor relief and gravity anomalies based on satellite altimetry. The oldest rocks deposited in these domains are represented by metamorphic basement rocks in the eastern part of Graham Land and represent the Gondwana basement of the Peninsula (Fig. 2).

Other complexes include intrusive and effusive rocks. Intrusive rocks belong to the batholiths of the Antarctic Peninsula (AP batholiths) of the Mezo-Cenozoic age. Volcanic rocks of the Antarctic Peninsula (AP Volcanic Group) are of the upper Jurassic age. They are composed of andesite rocks, pyroclastic rocks, and intrusive rocks with gabbroids and granitoids (Bakhmutov et al., 2013).

The Penola Strait - Lemaire Channel fault area is located within the influence of seismically dangerous Scotia Arc, encircling the Scotia Sea and the Drake Passage, and includes the South Georgia Island, South Sandwich Islands, South Shetland Islands, and South Orkney Islands. The interaction of two lithosphere plates South American and the Antarctic Plate causes a complex geodynamic situation and earthquakes. The largest earthquake in the region was recorded in 1971 with a magnitude of M7.0. Also, there were recorded 45 earthquakes with a magnitude greater than M5.0 over the past 50 years. Focal mechanisms of earthquakes demonstrate shallow hypocenters and normal and strike-slip mechanisms for faults (Pelayo and Wiens, 1989; Gonzalez-Casado et al., 2000; Robertson et al., 2003a). Liashchuk (2014) and Liashchuk and Karyagin (2018) notes that the average distance from earthquake centers to the Penola Strait Lemaire Channel fault area is $1000-2000 \mathrm{~km}$, however, the nearest earthquakes were registered at a distance of 150-200 km (M5.4). The authors also note that a huge number of local high-frequency seismic signals have been registered in the study region. Such seismic signals are not related to tectonic processes, but are caused by glaciers dynamic processes (Liashchuk and Karyagin, 2018). 


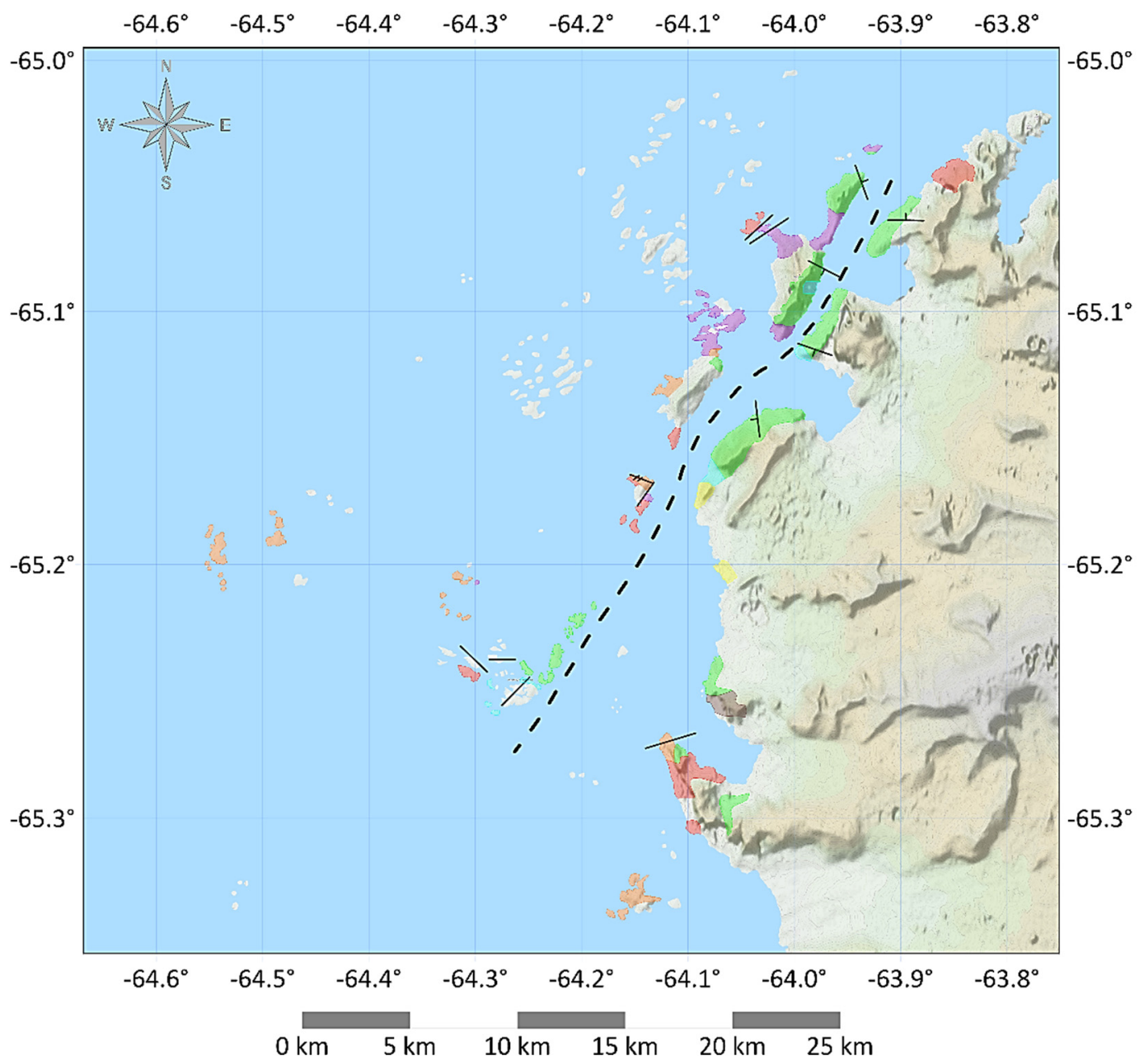

Fig. 2 Geological structure of the Penola Strait - Lemaire Channel fault area ( $\square$ - Pyroclastic rocks; $\square$ - Tonalite, Auguite-tonalite; $\square$ - Granodiorite; $\square$ - Gabdro, Olivine-gabbro, Hornblendegabbro; $\square$ - Andesite; - Diorite; $\square$ - Granite; _ _ _ _ - Penola Strait - Lemaire Channel fault; - Fault, definite tick on downthrown side; - Fault or dyke). The map was compiled using Curtis (1966), Geological map of the Southern Graham Land (1981), Ryan (2007), Mytrokhyn et al. (2017, 2018) with author's corrections and additions

\section{GEODYNAMIC MONITORING POLYGON OF PENOLA STRAIT - LEMAIRE CHANNEL FAULT AREA}

In February-March 2003, a geodynamic monitoring polygon for the Penola Strait - Lemaire Channel fault area was laid near the Ukrainian Antarctic Station "Academic Vernadsky". The founded geodynamic polygon is based on 2 base epoch GNSS stations and 14 monitoring epoch GNSS stations. The base epoch GNSS stations are sc98 and sc02, which are incorporated within the SCAR98/GAP98 and SCAR GPS 2002 campaigns (Dietrich, 2001; Dietrich and Rülke, 2002). The locations of all epoch GNSS stations of the geodynamic polygon were selected considering the geological structure of the region and the openness of the horizon for the application of GNSS observation. The geodynamic polygon epoch GNSS stations are located on both sides of the Penola Strait and Lemaire Channel (Fig. 3), on the west side on the
Roca Islands, Barchans Islands, Galindez Island, Fanfare Island, Irizar Island, Petermann Island, Hovgaard Island, Booth Island and Splitwind Island, and on the east side - on the Kyiv Peninsula, Berthelot Islands and Yalour Islands.

The exterior of the centers of the base epoch GNSS stations is a brass mark $70 \mathrm{~mm}$ in diameter screwed into the rock; instead, the outer part of the centers of the monitoring epoch GNSS stations is a steel rod up to $400 \mathrm{~mm}$ in length, which is concreted into the rock. At all epoch GNSS stations of the geodynamic polygon, forced centering of antennas of GNSS receivers is provided.

The geodynamic polygon extends north east along the Penola Strait and Lemaire Channel and covers an area of approximately $350 \mathrm{~km}^{2}$. The average distance between epoch GNSS stations is $9.3 \mathrm{~km}$, the maximum distance is $28.9 \mathrm{~km}$, and the minimum distance is $8 \mathrm{~m}$. The elevation of epoch GNSS stations in the WGS-84 system is within $18-35 \mathrm{~m}$. 


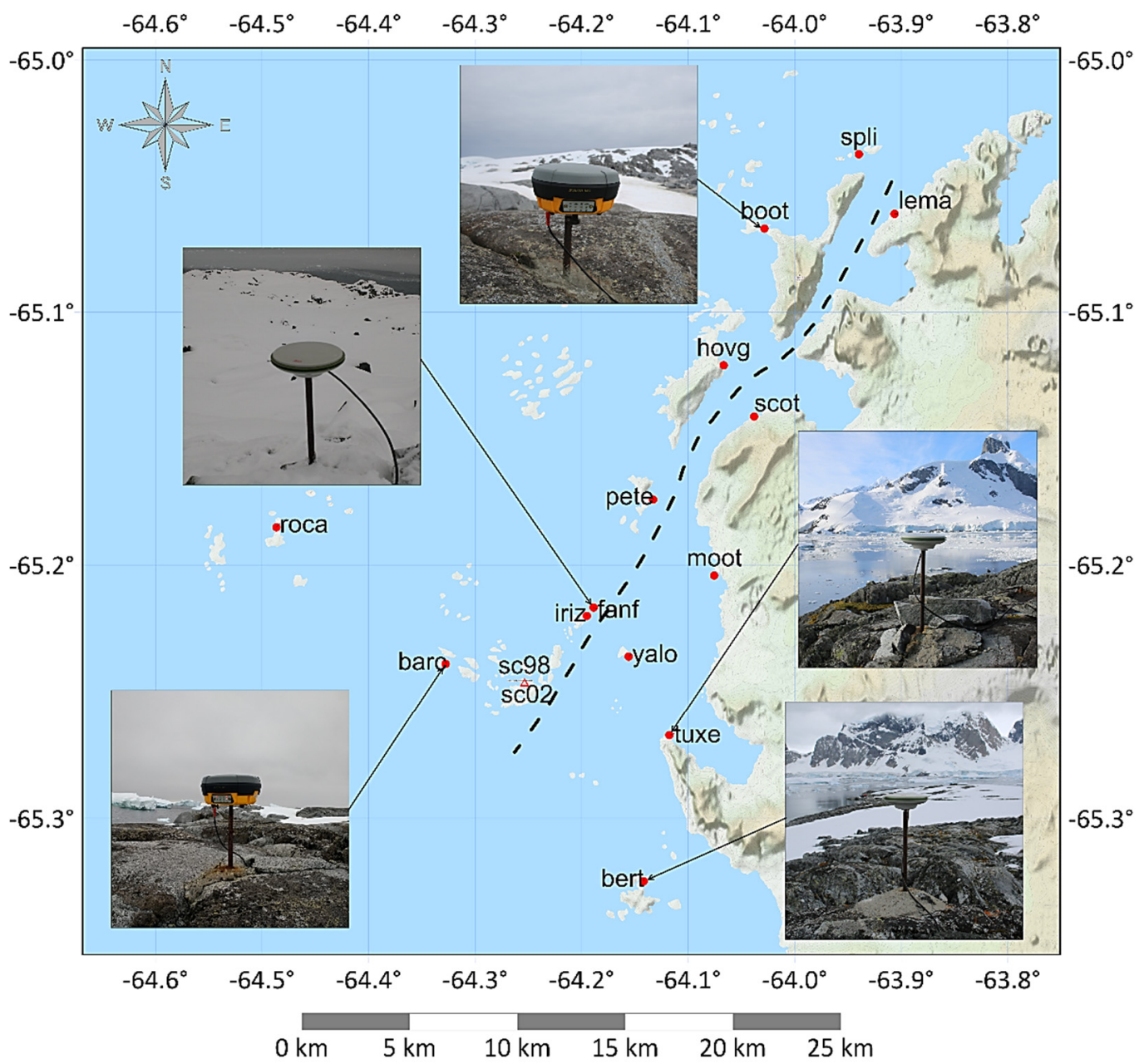

Fig. 3 Geodynamic monitoring polygon of the Penola Strait - Lemaire Channel fault area ( $\Delta-$ base epoch GNSS stations; $\bullet$ - monitoring epoch GNSS stations; - - - _ - Penola Strait - Lemaire Channel fault).

Geodynamic monitoring polygon also serves as a terrestrial reference geodetic network for the implementation of topographic and geodetic works in the area of the Ukrainian Antarctic Station "Academic Vernadsky".

\section{ANALYSIS OF THE GNSS CAMPAIGNS OBSERVATION}

Since 2003, 5 seasonal cycles of static GNSS observation have been carried out at the geodynamic polygon. The static GNSS observations are considered to be the classical GNSS method which delivers the highest available accuracy. The precision of the position is a function of the length of observation and also the precision of the mounting and monument system used. The length of the GNSS observation session depends on the length of the lines, the number of simultaneously visible satellites, the type of receivers and the required accuracy. It should be noted that some items could not be measured due to the very difficult Antarctic weather conditions, as well as the lack of time in some cycles of static GNSS observation.
To reduce the impact of systematic errors, as well as to improve the accuracy of GNSS observation at all epoch GNSS stations of the geodynamic polygon in each cycle, several sessions of static GNSS observation were conducted. To ensure different geometry of satellites, GNSS observation sessions were conducted at different times of the day. The total observation time at each epoch GNSS stations, over one cycle, ranged from 5 to 64 hours.

Table 1 shows the technical characteristics of all cycles of static GNSS observation at the epoch GNSS stations of the geodynamic polygon.

The processing of static GNSS observation was performed in Leica GeoOffice Software Version 8.2. A special GNSS data processing strategy was used in processing (Savchyn and Pronyshyn, 2020). All measurement cycles were processed using this strategy. The key parameters of the GNSS data processing strategy are shown in Table 2.

Absolute calibrations of the phase centers of the antennas were used in ANTEX format. Due to the lack of absolute calibrations for some antennas used in the first two cycles of static GNSS observation, the stability of the phase centers was tested using a specially developed technique (Tretyak et al., 2002). 
Table 1 Technical characteristics of all cycles of static GNSS observation at the epoch GNSS stations of the geodynamic polygon of the Penola Strait - Lemaire Channel fault area.

\begin{tabular}{|c|c|c|c|c|}
\hline \multirow{2}{*}{$\begin{array}{l}\text { GNSS } \\
\text { cycle }\end{array}$} & \multirow{2}{*}{$\begin{array}{l}\text { GNSS } \\
\text { epoch }\end{array}$} & \multirow{2}{*}{$\begin{array}{c}\text { Epoch GNSS } \\
\text { stations }\end{array}$} & \multicolumn{2}{|c|}{ GNSS equipment } \\
\hline & & & GNSS receiver & GNSS antenna \\
\hline \multirow{4}{*}{ I } & \multirow{4}{*}{$\begin{array}{l}\text { February } \\
2003\end{array}$} & \multirow{4}{*}{$\begin{array}{l}\text { sc02, bert, barc, fanf, yalo, } \\
\text { pete, roca, tuxe }\end{array}$} & Leica SR-399 & LEIAT303 NONE \\
\hline & & & Leica SR-9500 & LEISR299_INT NONE \\
\hline & & & Trimble 4600LS & TRM4800 NONE \\
\hline & & & Trimble 4800 & (2 it.) \\
\hline \multirow{4}{*}{ II } & \multirow{4}{*}{$\begin{array}{c}\text { March- } \\
\text { April } \\
2005\end{array}$} & \multirow{4}{*}{$\begin{array}{l}\text { sc02, sc } 98, \text { bert, barc, fanf, } \\
\text { yalo, pete, roca, tuxe }\end{array}$} & Ashtech Z-12 & ASH700936B_M NONE \\
\hline & & & Javad HiPer GGD & JPSMARANT_'̄GGD NONE \\
\hline & & & Leica SR-399 & 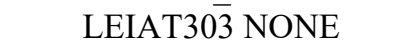 \\
\hline & & & Leica SR-9500 & LEISR299 INT NONE \\
\hline \multirow{4}{*}{ III } & \multirow{4}{*}{$\begin{array}{l}\text { April } \\
2014\end{array}$} & \multirow{4}{*}{$\begin{array}{l}\text { sc02, barc, fanf, yalo, pete, } \\
\text { tuxe, iriz }\end{array}$} & Leica GPS1200 & LEIAX1202GG NONE \\
\hline & & & (2 it.) & LEIAX1203+GNSS NONE \\
\hline & & & Trimble R7 & TRM55971.00 NONE \\
\hline & & & (2 it.) & TRM29659.00 SCIS \\
\hline \multirow{3}{*}{ IV } & \multirow{3}{*}{$\begin{array}{c}\text { March- } \\
\text { April } \\
2018 \\
\end{array}$} & \multirow{3}{*}{$\begin{array}{l}\text { sc02, sc98, barc, fanf, yalo, } \\
\text { pete, tuxe }\end{array}$} & Leica GPS1200 & LEIAX1202GG NONE \\
\hline & & & (2 it.) & LEIAX1203+GNSS NONE \\
\hline & & & outh S82T-2013 (2 it.) & STHS82HX-BS601A NONE \\
\hline \multirow{4}{*}{ V } & \multirow{4}{*}{$\begin{array}{c}\text { February- } \\
\text { April } \\
2018\end{array}$} & \multirow{4}{*}{$\begin{array}{c}\text { sc02, sc98, bars, barc, fanf, } \\
\text { yalo, pete, roca, tuxe, iriz, } \\
\text { boot, moot, hovg, spli, scot, } \\
\text { lema }\end{array}$} & Leica GPS1200 & LEIAX1202GG NONE \\
\hline & & & (2 it.) & LEIAX1203+GNSS NONE \\
\hline & & & South S82T-2013 & STHS82HX-BS601A NONE \\
\hline & & & & \\
\hline
\end{tabular}

Table 2 GNSS data processing strategy.

\begin{tabular}{|c|c|c|}
\hline Parameter & Characteristic & Description \\
\hline GNSS type & GPS/GLONASS & System combine GPS and GLONASS data. \\
\hline Frequency & Automatic & $\begin{array}{l}\text { System automatically select the best frequency or combination of } \\
\text { frequencies for the final solution. }\end{array}$ \\
\hline Solution type & Automatic & $\begin{array}{l}\text { System use code and phase observations for the computation and to } \\
\text { resolve the ambiguities. If, for some reason, only code or phase } \\
\text { measurements are available the system automatically switches to use } \\
\text { exclusively these measurements for computation. }\end{array}$ \\
\hline Sampling rate & 5 seconds & System use 5 seconds sampling rate for GNSS data processing. \\
\hline Ephemeris & Precise & $\begin{array}{c}\text { System use GPS and GLONASS Final Orbits in NOAA/NGS SP3 } \\
\text { format (Standard Product 3). }\end{array}$ \\
\hline Cut-off angle & $10^{\circ}$ & $\begin{array}{l}\text { System cut-off the noisier low elevation satellites (lower } 10^{\circ} \text { ) to } \\
\text { reduce the overall phase noise. }\end{array}$ \\
\hline $\begin{array}{l}\text { Tropospheric } \\
\text { model }\end{array}$ & Hopfield & $\begin{array}{l}\text { System use Hopfield model to account the impact of the tropospheric } \\
\text { delay. }\end{array}$ \\
\hline $\begin{array}{c}\text { Ionospheric } \\
\text { model }\end{array}$ & Automatic & $\begin{array}{l}\text { System automatically computes an ionospheric model. This is } \\
\text { advantageous, as the model computed is in accordance with } \\
\text { conditions prevalent at the time and position of observation. }\end{array}$ \\
\hline Processing mode & All baselines & System process of all possible combinations of baselines. \\
\hline Terrestrial frame & ITRF2014 & $\begin{array}{c}\text { ITRF2014 (Altamimi et. al., 2016) is used as a terrestrial frame in } \\
\text { processing. }\end{array}$ \\
\hline
\end{tabular}

Three IGS GNSS stations were included to processing to specify the coordinate system: PALM (Palmer Station - 64ำ $46^{\prime} 30^{\prime \prime} \mathrm{S}, 6^{\circ} 03^{\prime} 04^{\prime \prime} \mathrm{W}$ ), DUPT

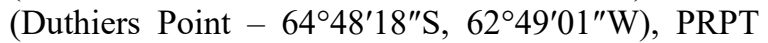
(Prospect Point $-66^{\circ} 00^{\prime} 24^{\prime \prime} \mathrm{S}, 65^{\circ} 20^{\prime} 22^{\prime \prime} \mathrm{W}$ ).

Unfortunately, in this software, it is not possible to consider the models of Earth deformation for example caused by ocean tidal loading, atmospheric pressure loading, gravitational effects, and others.
Obviously, such models could improve the accuracy of the solutions, but their use in this study is not critically necessary because the research area is quite small.

As a result of processing of static GNSS observation, the coordinates of the epoch GNSS stations of the geodynamic polygon and the standard errors of their determination were obtained. The standard error of determination of the planar 


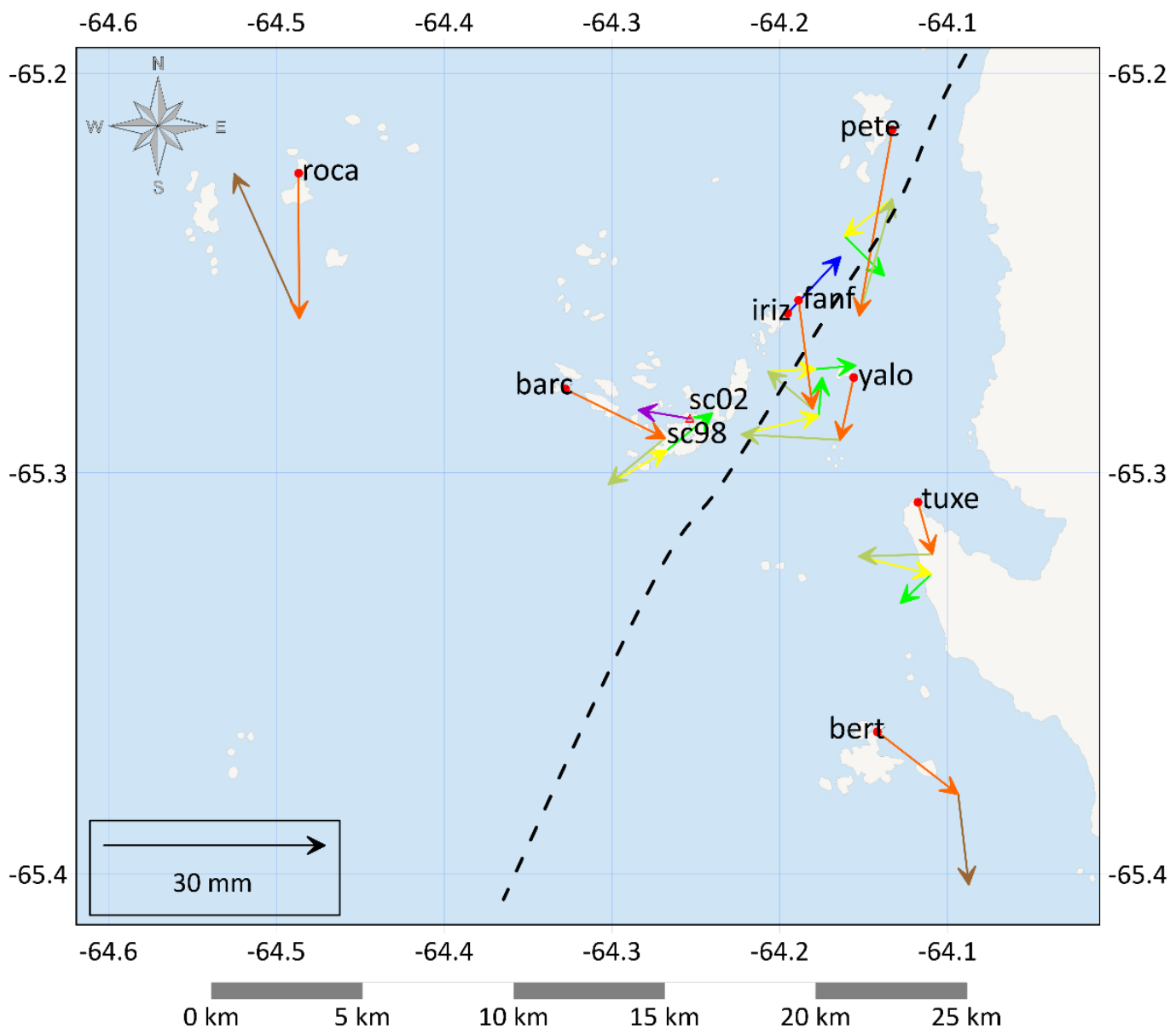

Fig. 4 Scheme of the horizontal movements of the epoch GNSS stations of the geodynamic polygon of the Penola Strait - Lemaire Channel fault area determined during 2003-2019 ( $\Delta$ - base epoch GNSS stations; - - monitoring epoch GNSS stations; _ _ _ _ - Penola Strait - Lemaire Channel fault; $\longrightarrow$ - 2005-2003 ; $\longrightarrow-2014-2005 ; \longrightarrow-2018-2014 ; \longrightarrow-2019-2018 ; \longrightarrow-2019-2014 ; \longrightarrow-2018-2005$; $\longrightarrow$-2019-2005).

coordinates fluctuates within $2 \mathrm{~mm}$ and the elevation within $3 \mathrm{~mm}$.

Based on the determined coordinates, horizontal movements of the epoch GNSS stations of the geodynamic polygon for all observation cycles are calculated. Figure 4 presents a diagram of the horizontal movements of the epoch GNSS stations of the geodynamic polygon determined during 20032019 in different cycle of static GNSS observation.

Analyzing the presented scheme (Fig. 4) it can be noticed that the vectors of horizontal movements of the epoch GNSS stations of the polygon are multidirectional, but most of them (37\%) indicate the south and south east direction. The lengths of the determined vectors of horizontal movements of the polygon epoch GNSS stations are different, which indicates the uneven velocity of horizontal movements of the studied area. For example, the maximum horizontal movements were observed at pete (on Petermann Island) between 2003 and $2005-27.4 \mathrm{~mm}$, and between 2005 and $2014-16.0 \mathrm{~mm}$, and at roca (on Roca Islands) between 2003 and $2005-19.8 \mathrm{~mm}$. Instead, minimum horizontal movements were observed at fanf (on Fanfare Island) between 2018 and $2019-3.1 \mathrm{~mm}$, and between 2014 and $2018-3.7 \mathrm{~mm}$, as well as at tuxe (on Cape Tuxen) between 2018 and $2019-3.0 \mathrm{~mm}$.

It should be noted that for epoch GNSS stations hovg, boot, split, lema, scot and moot it is impossible to determine the vectors of horizontal and vertical movements, as they were installed in 2019 and only one cycle of static GNSS observation was performed. Therefore, in this research, the monitoring of recent local geodynamic activity in the south west part of Penola Strait - Lemaire Channel fault area was carried out. Instead, monitoring of the north east part of Penola Strait - Lemaire Channel fault area as well as monitoring of all Penola Strait - Lemaire Channel fault area is a promising topic for further research.

\section{GEODYNAMIC INTERPRETATION OF THE RESULTS}

The results of the GNSS campaigns were used to determine recent local geodynamic processes in the Penola Strait - Lemaire Channel fault area. For this purpose, the transition from the calculated vectors of 


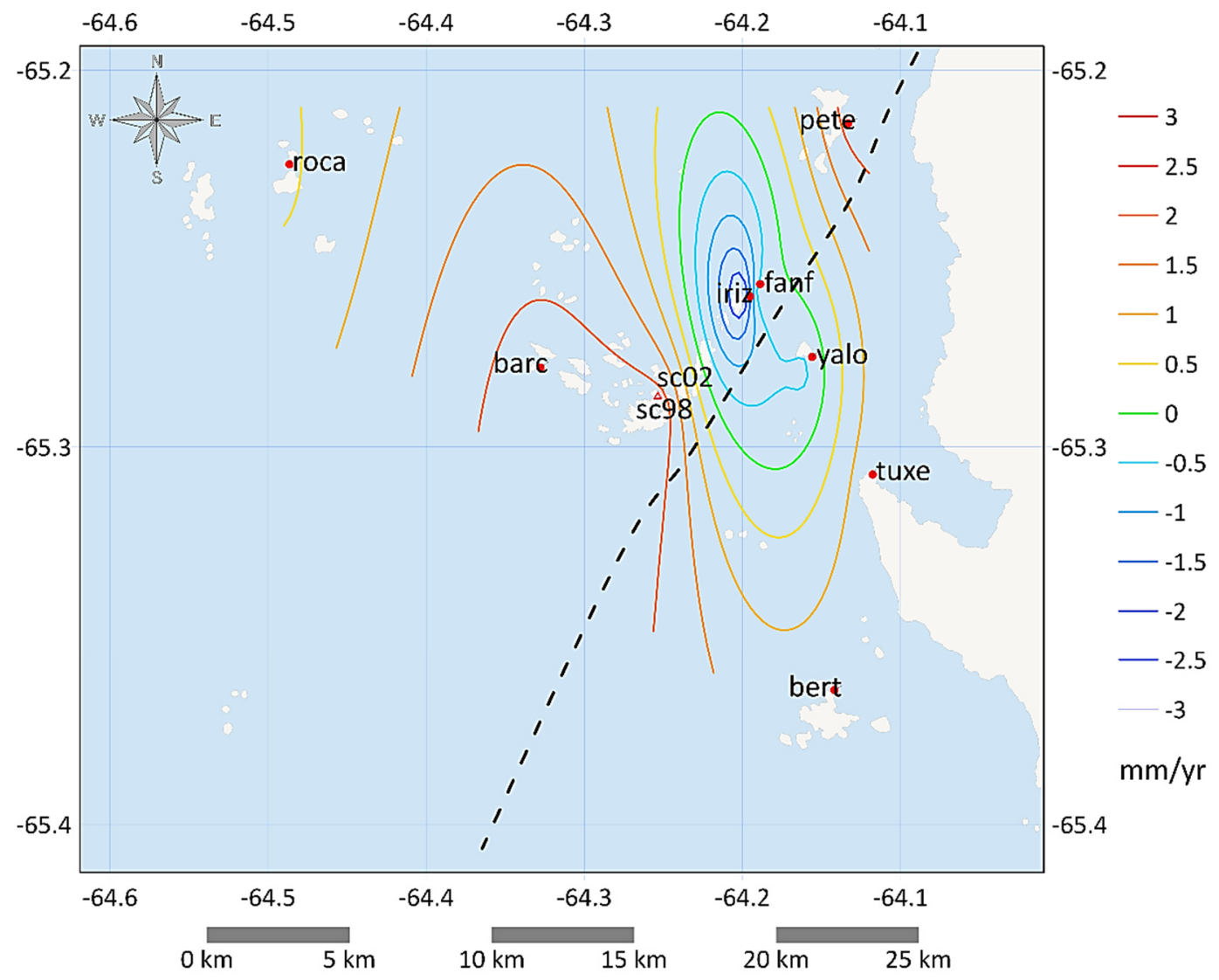

Fig. 5 Spatial distribution of the velocity field of vertical movements in Penola Strait - Lemaire Channel fault area ( $\Delta$ - base epoch GNSS stations; $\bullet$ - monitoring epoch GNSS stations; - - - - - Penola Strait - Lemaire Channel fault).

horizontal and vertical movements of the polygon epoch GNSS stations to their average linear velocities over a given period was performed (Table 2).

The obtained values of the average linear velocities of vertical movements of the geodynamic polygon epoch GNSS stations were used to illustrate the spatial distribution of the velocity field of vertical movements in Penola Strait - Lemaire Channel fault area (Fig. 5).

Analyzing the spatial distribution of the vertical movements velocity field (Fig. 5), it can be observed that, in general, the Penola Strait - Lemaire Channel fault area is uplifting, but a small lowering zone is identified in the Irizar Island area (approximate radius $1.4 \mathrm{~km}$ ). The range of vertical velocities varies from -2.5 to $+2.5 \mathrm{~mm} / \mathrm{yr}$. The rise in the Barchans Islands is confirmed by the results of the static GNSS observation in Kylchitskiy et al. (2010) and Tretyak et al. (2016). The rise of the Penola Strait - Lemaire Channel fault area and all Antarctic Peninsula is confirmed by Hardy (2019), using a combination of time-variable gravimetry, altimetry, and GNSS. Bevis et al. (2009) noted that the velocities of vertical movements of GNSS stations on the Antarctic Peninsula also have positive values. Moreover, for the GNSS station PALM (Palmer Station), which is $15 \mathrm{~km}$ away from the geodynamic polygon, the velocity of vertical movements is $+4.1 \mathrm{~mm} / \mathrm{yr}$.
The values of the calculated average linear velocities of the horizontal movements are quite small and are in the range of $0.3-1.8 \mathrm{~mm} / \mathrm{yr}$. The highest values of the average linear velocities of horizontal movements of 1.2 and $1.8 \mathrm{~mm} / \mathrm{yr}$ are observed at barc (on the Barchans Islands) and iriz (on Irizar Island) respectively. It is interesting that fanf (on Fanfare Island) and yalo (on the Yalour Islands) are rotating clockwise at the average linear velocity of 0.5 and $0.6 \mathrm{~mm} / \mathrm{yr}$ respectively, but in return pete (on Petermann Island) undergoes a gradual rotation in a counter-clockwise direction with an average linear velocity of $0.8 \mathrm{~mm} / \mathrm{yr}$ (Fig. 4). All other epoch GNSS stations undergoes curvilinear movements. The obtained results correlate well with Dietrich et al. (2004), stating that the relative horizontal movements of GNSS stations on the Antarctic Peninsula do not exceed $2.0 \mathrm{~mm} / \mathrm{yr}$.

For detailed analysis and interpretation of the average linear velocities of horizontal movements in the Penola Strait - Lemaire Channel fault area, the dilatation parameters (area change) are used which characterize the relative expansion (increase in area) or compression (area decrease) of the territory, as well as the total shear characterizing the horizontal heterogeneity of the deformed territory. Based on the analysis of previous studies conducted on the Antarctic Peninsula (Tretyak and Golubinka, 
2006), the northern Tian Shan (Kostiuk et al., 2010), the south-eastern Europe (Marchenko et al., 2012), Europe (Tretyak and Vovk, 2014), the northern part of Egypt (Mohamed et al., 2016) it was found that dilatation and total shear parameters are optimal for a detailed analysis and interpretation of recent local geodynamic processes of the studied area.

The dilatation and total shear parameters were determined for a regular grid at $1000 \mathrm{~m}$ increments using a mathematical algorithm based on tensor analysis (Shen et al., 1996; Sagiya et al., 2000; Abdel-Monem et al., 2011; Mohamed et al., 2016):

$\Delta=e_{x x}+e_{y y}$

$\gamma=\sqrt{\left(e_{x x}-e_{y y}\right)^{2}+\left(2 e_{x y}\right)^{2}}$

where $e_{x x}, e_{y y}$ and $e_{x y}$ are components of the Earth's surface strain rate tensor.

The components of the strain rate tensor can be defined as follows (Shen et al., 1996; Sagiya et al., 2000; Abdel-Monem et al., 2011; Mohamed et al., 2016):

$$
\begin{aligned}
& e_{x x}=\frac{1}{\Delta t} \cdot \frac{\partial u}{\partial x}, \\
& e_{y y}=\frac{1}{\Delta t} \cdot \frac{\partial v}{\partial y}, \\
& e_{x y}=\frac{1}{2 \Delta t} \cdot\left(\frac{\partial u}{\partial y}+\frac{\partial v}{\partial y}\right),
\end{aligned}
$$

where $(u, v)$ are the movements at the epoch GNSS stations during the time interval $\Delta t$ in the directions of $(x, y)$.

The obtained dilatation values were used to illustrate its spatial distribution in the Penola Strait Lemaire Channel fault area (Fig. 6). Analysis of the distribution of the Earth's surface dilatation velocity fields in the Penola Strait - Lemaire Channel fault area (Fig. 6) reveals locations of extreme compression (greater than +0.02 micro-strain) and expansion (smaller than -0.2 micro-strain), showing the increased geodynamic activity.

Two expansion zones are identified in the Penola Strait - Lemaire Channel fault area. The first expansion zone (approximate radius $2.9 \mathrm{~km}$ ) is identified on the Barchans Islands and Anagram Islands. The dilatation velocity range of the first expansion zone varies from +0.025 to +0.338 microstrain. The selected zone is characterized by expansion in the submedian direction. The second expansion zone is much smaller (approximate radius of $0.5 \mathrm{~km}$ ) is identified on the Yalour Islands. The dilatation velocity range of the second expansion zone varies from +0.024 to +0.254 micro-strain. The expansion axes of this zone have a north east direction.

There are also three compression zones identified in Penola Strait - Lemaire Channel fault area. The first compression zone (approximate radius $1.8 \mathrm{~km}$ ) is identified in the Barros Rocks area. The dilatation range of the first compression zone varies from -0.023 to -0.081 micro-strain. The selected zone is characterized by compression in the meridional direction. The second compression zone (approximate size is $1.8 \mathrm{~km}$ by $5.2 \mathrm{~km}$, extended in the $\mathrm{N}$ direction) is identified on the Black Island, Leopard Island, Skua Island, Shelter Islands, Three Little Pigs Islands and Forge Islands. The dilatation range of the second compression zone varies from -0.023 to -0.087 microstrain. The compression axes of this zone have a NW direction. The results obtained in this zone confirm the assumption made by Bakhmutov $(1998,2006)$ about the presence of tectonic activity on the Three Little Pigs Islands, as well as a statement made by Maksymchuk et al. in $(2002,2009)$ that the most intensive tectonomagnetic anomalies were defined on the Three Little Pigs Islands. The third compression zone (approximate size is $1.5 \mathrm{~km}$ by $5.4 \mathrm{~km}$, extending north east) is identified on the Fanfare Island and Irizar Island. The dilatation velocity range of the third compression zone varies from -0.021 to -0.083 microstrain. The selected zone is characterized by compression in the submedian direction. The third compression zone is of considerable scientific interest because it coincides with the extension of the Penola Strait - Lemaire Channel fault area. This zone also coincides with the zone of slight lowering of the Irizar Island area (Fig. 5).

The obtained values of the total shear are used to illustrate its spatial distribution in the Penola Strait Lemaire Channel fault area (Fig. 7). In order to avoid any distortion of the results, all zones in which the values of the Earth's surface total shear velocity were within 0.04 micro-strain and were considered stable. The total shear accuracy is within \pm 0.005 micro-strain.

As a result of the analysis of the distribution of the Earth's surface total shear velocity in the Penola Strait - Lemaire Channel fault area (Fig. 7), it is established that the locations of the maximum values of the total shear (more than 0.04 micro-strain) coincide with the identified compression and expansion zones of the studied area (Fig. 6). It can also be noted that the total shear vectors are multidirectional, which indicates the horizontal heterogeneity of the studied area.

Data from Global Multi-Resolution Topography (GMRT) synthesis (Ryan et al., 2009) suggest that there is another fault that coincides with the direction of the French Passage fairway and is almost perpendicular to the Penola Strait - Lemaire Channel fault. An additional argument for the existence of the French Passage fault is the spatial distribution of the vertical movement velocity field in the area (Fig. 5). The determined stresses in the tectonic blocks suggest the nature of the kinematic type of the Penola Strait Lemaire Channel fault area (Fig. 8).

This fault can be described as a combination of strike -slip and thrust, commonly known as transpressive (Sanderson and Marchini, 1984; Fossen and Tikoff, 1998). Such structures are widely described in the geological literature. They are known in all tectonic regimes. Transpressional faults are that characterized by a shortening structure with parallel shearing ones. 


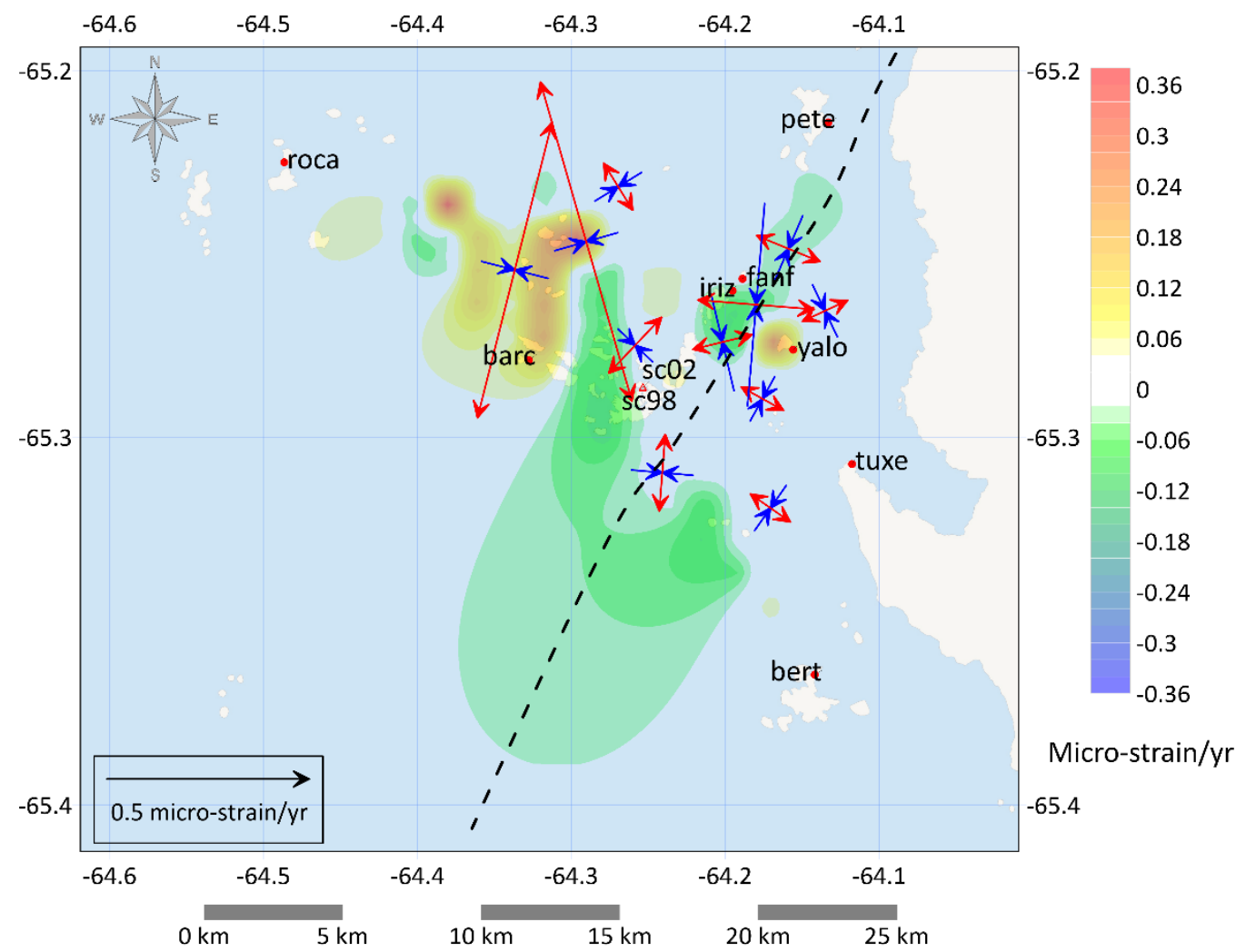

Fig. 6 Spatial distribution of the Earth's surface dilatation velocity in the Penola Strait - Lemaire Channel fault area ( $\Delta$ - base epoch GNSS stations; - - monitoring epoch GNSS stations; - - - - - Penola Strait Lemaire Channel fault; $\rightarrow \leftarrow-$ directions of area compression; $\leftarrow \rightarrow-$ directions of area expansion).

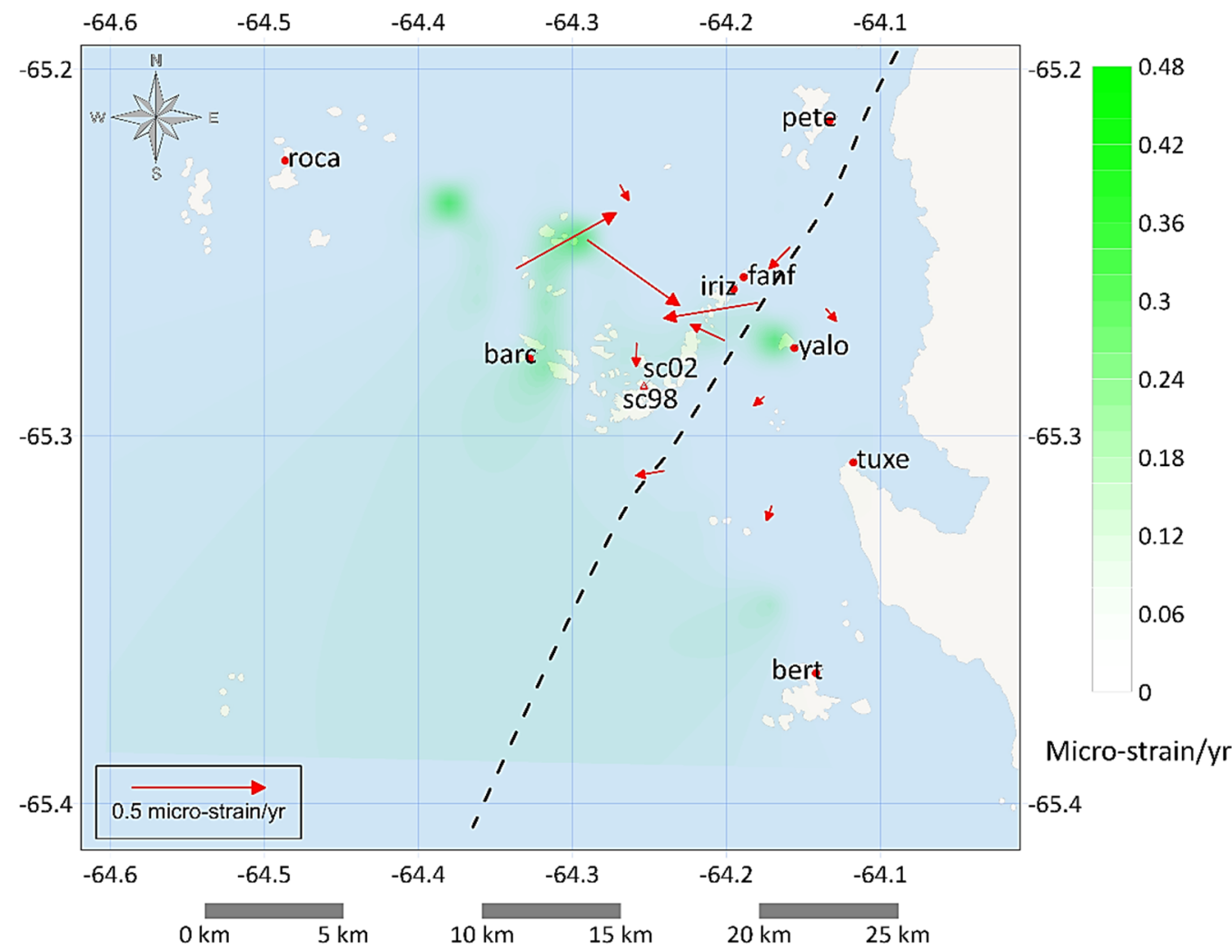

Fig. 7 Spatial distribution of the Earth's surface total shear velocity in the Penola Strait - Lemaire Channel fault area $(\Delta-$ base epoch GNSS stations; $\bullet-$ monitoring epoch GNSS stations; - - - - - Penola Strait Lemaire Channel fault; $\rightarrow-$ the direction of a total shear vector). 


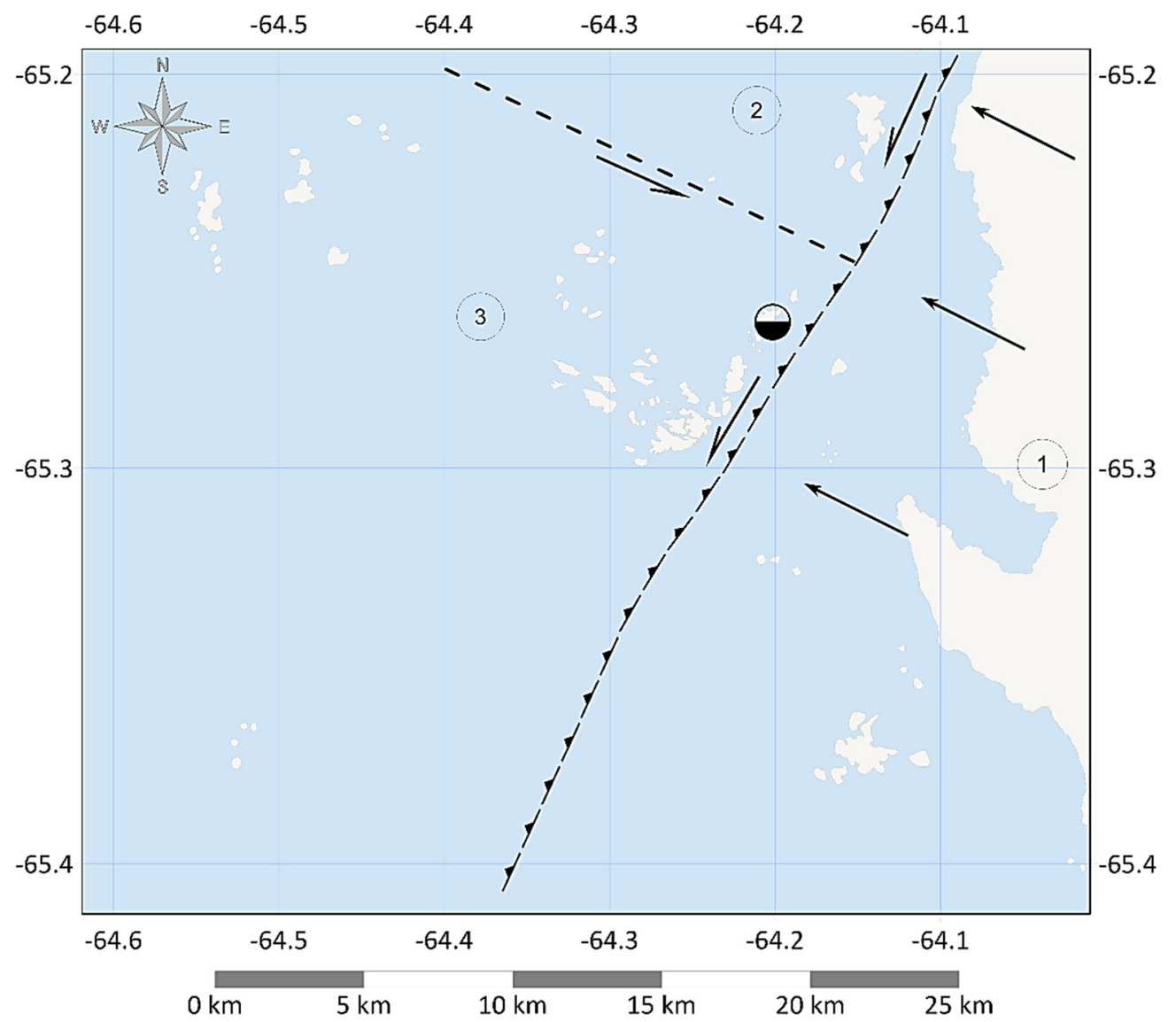

Fig. 8 Kinematic model of the tectonic blocks in the Penola Strait - Lemaire Channel fault area (_ _ _ _ - Fault, inferred; $\_$- thrust fault; 1 - number of tectonic block $\boldsymbol{Q}$ - lowering zone; $\rightarrow$ - the direction of an area movements).

That are tectonic blocks 2 and 3 which are to the left of the fault, move in the south east direction to tectonic block 1 with simultaneous sinistral strike-slip. Such processes cause the lowering of the tectonic block 3 adjacent to the Penola Strait - Lemaire Channel fault area. The presented model is preliminary and is based solely on currently available GNSS measurements. Its further development should be based on expanded research areas in the region, as well as a combination of GNSS and other possible geophysical methods.

\section{CONCLUSIONS AND DISCUSSION}

The example of the geodynamic polygon of the Penola Strait - Lemaire Channel fault area demonstrates the possibility of using static GNSS observation to study recent local geodynamic processes in Antarctica.

The processing of static GNSS observation was performed in Leica GeoOffice Software Version 8.2. Obtained solutions fully satisfy the objectives of the study. Possibly, solutions could be improved using scientific software such as Bernese GNSS Software, GAMIT/GLOBK, GipsyX, or others, but this requires further research.

As a result of the study, it is established that active local geodynamic processes are occurring in the
Penola Strait - Lemaire Channel fault area. The values of the calculated horizontal movements vectors are multidirectional and are in the range $0.3-1.8 \mathrm{~mm} / \mathrm{yr}$, and the values of the vertical movements vectors are in the range $-2.7-+2.4 \mathrm{~mm} / \mathrm{yr}$.

The Penola Strait - Lemaire Channel fault area identifies two major zones of extreme expansion values and three major zones of extreme compression, as well as one lowering zone that is clearly caused by active tectonic processes. The most active recent local geodynamic processes are recorded in the Irizar Island area.

A new proposed kinematic model of the Penola Strait - Lemaire Channel fault area is based on the analysis of static GNSS observation taken during 2003-2019. This model is significantly different from the previous one.

However, the presented results obtained on the basis of periodic static GNSS observation do not allow the identification of short-term recent local geodynamic processes, so in order to find and observe such processes it is advisable to increase the frequency of observation cycles, and in order to monitor continuously and evaluate the danger it is recommended to provide permanent GNSS monitoring network in the Penola Strait - Lemaire Channel fault area. 


\section{ACKNOWLEDGEMENTS}

This geodetic and geodynamics research has been carried out with the support of the State Institution National Antarctic Scientific Center of Ukraine. The primary data and materials for the study were obtained from the 8th, 10th, 14th, 23rd, 24th seasonal Ukrainian Antarctic expedition. Also, we are grateful to the reviewers for their very constructive and useful comments on the manuscript.

\section{REFERENCES}

Abdel-Monem, S.M., Mahmoud, S., Shaker, A., Saad, A. and Hamed, M.: 2011, Crustal deformation studies in the northern part of Aswan Lake using GPS technique. NRIAG J. Geophys. Spec. Issue, 89-110.

Altamimi, Z., Rebischung, P., Métivier, L. and Collilieux, X.: 2016, ITRF2014: A new release of the International Terrestrial Reference Frame modeling nonlinear station motions. J. Geophys. Res., Solid Earth, 121, 8, 6109-6131. DOI: $10.1002 / 2016 J B 013098$

Bakhmutov, V.: 1998, Geological review of Argentine islands archipelago and adjoining territory of the Antarctic Peninsula. Bull. UATs, 2, 77-84. (in Russian).

Bakhmutov, V.: 2006, Evolution and geodynamics of the main structures of the Western Antarctic in MezoCenozoic: modern conception. Ukrayinskyy antarktychnyy zhurnal, 4-5, 52-63, (in Russian).

Bakhmutov, V., Gladkochub, D. and Shpyra, V.: 2013, Age position, geodynamic specifics and palaeomagnetism of intrusive complexes of the western coast of the Antarctic Peninsula. Geofizicheskiy Zhurnal, 35, 3, 3-30. DOI: $10.24028 /$ gzh.0203-3100.v35i3.2013.116387

Barker, P.F.: 1982, The Cenozoic subduction history of the Pacific margin of the Antarctic Peninsula: ridge cresttrench interactions. J. Geol. Soc., 139, 6, 787-801. DOI: $10.1144 /$ gsjgs. 139.6 .0787

Berrocoso, M., Fernández-Ros, A., Prates, G., García, A. and Kraus, S.: 2016, Geodetic implications on block formation and geodynamic domains in the South Shetland Islands, Antarctic Peninsula. Tectonophysics, 666, 211-219.

DOI: 10.1016/j.tecto.2015.10.023

Bevis, M., Kendrick, E., Smalley Jr, R., Dalziel, I., Caccamise, D., Sasgen, I. and Raleigh, D.: 2009, Geodetic measurements of vertical crustal velocity in West Antarctica and the implications for ice mass balance. Geochem. Geophys. Geosyst., 10, 10. DOI: 10.1029/2009GC002642

Curtis, R.: 1966, The petrology of the Graham coast, Graham Land. Antartic Survey Scientific Reports, 50. British Antarctic Survey.

Dietrich, R.: 2001, Present status of the SCAR GPS epoch campaigns. SCAR Report, 20, 15-18.

Dietrich, R. and Rülke, A.: 2002, The SCAR GPS campaigns in the ITRF2000. SCAR Report 21, 10-11.

Dietrich, R., Rülke, A., Ihde, J., Lindner, K., Miller, H., Niemeier, W., ... and Seeber, G.: 2004, Plate kinematics and deformation status of the Antarctic Peninsula based on GPS. Glob. Planet. Change, 42, 14, 313-321. DOI: 10.1016/j.gloplacha.2003.12.003

Ferraccioli, F., Jones, P.C., Vaughan, A.P.M. and Leat, P.T.: 2006, New aerogeophysical view of the Antarctic Peninsula: More pieces, less puzzle. Geophys. Res. Lett., 33, 5. DOI:_10.1029/2005GL024636
Fossen, H. and Tikoff, B.: 1998, Extended models of transpression and transtension, and application to tectonic settings. Geol. Soc. London, Spec. Publ., 135, 1, 15-33. DOI: 10.1144/GSL.SP.1998.135.01.02

Galindo-Zaldivar, J., Gamboa, L., Maldonado, A., Nakao, S. and Bochu, Y.: 2004, Tectonic development of the Bransfield Basin and its prolongation to the South Scotia Ridge, northern Antarctic Peninsula. Mar. Geol., 206, 1-4, 267-282.

DOI: $10.1016 /$ j.margeo.2004.02.007

Galindo-Zaldivar, J., Jabaloy, A., Maldonado, A. and De Galdeano, C.S.: 1996, Continental fragmentation along the South Scotia Ridge transcurrent plate boundary (NE Antarctic Peninsula). Tectonophysics, 258, 1-4, 275-301. DOI: $10.1016 / 0040-1951(95) 00211-1$

Geological map of the Southern Graham Land, 1:500000. BAS 500G Series.

González-Casado, J.M., Robles, J.L.G. and López-Martínez, J.: 2000, Bransfield basin, Antarctic peninsula: not a normal backarc basin. Geology, 28, 11, 1043-1046. DOI: $10.1130 / 0091-7613(2000) 28$

Gràcia, E., Canals, M., Farràn, M.L., Prieto, M.J., Sorribas, J. and Team, G.: 1996, Morphostructure and evolution of the central and eastern Bransfield basins (NW Antarctic Peninsula). Marine Geophys. Res., 18, 2-4, 429-448.

Hardy, R.A.: 2019, Combination of geodetic data over the Antarctic Ice Sheet for monthly mass variation solutions. Doctoral dissertation, University of Colorado at Boulder.

Jiang, W.P., Dong-Chen, E., Zhan, B.W. and Liu, Y.W.: 2009, New model of Antarctic plate motion and its analysis. Chin. J. Geophys., 52, 1, 23-32. DOI: $10.1002 /$ cjg2.1323

Kostiuk, A., Sychova, N., Yunha, S., Bohomolov, L. and Yagi, Y.: 2010, Deformation of the Earth's crust in the Northern Tien-Shan according the earthquake focal data and satellite geodesy. Izvestiya, Physics of the Solid Earth, 3, 52-65, (in Russian).

Kylchitskiy, A., Tretyak, K. and Golubinka, Y.: 2010, Detailed geodynamic model of Penola Fault (Antarctic Peninsula) on the base of geodetic measurements and geological-geophysical data. Geeodynamics, 9, 5-9, (in Ukrainian).

Larter, R. and Barker, P.F.: 1991, Effects of ridge cresttrench interaction on Antarctic-Phoenix spreading: forces on a young subducting plate. J. Geophys. Res., Solid Earth, 96, B12, 19583-19607.

DOI: $10.1029 / 91$ JB02053

LeicaGeoOffice LGO 8.2 Online Help Manual: 2008, Leica Geo Office: Heerbrugg, Switzerland, 2008. Available online: http://leicageosystems.com/products/total-stations/software/leica-geooffice (accessed on 27 April 2018)

Liashchuk, O.I. and Karyagin, Ye.V.: 2018, Features of seismicity in the Argentine Islands Archipelago Region due to the processes of icebergs formation. Ukrainian Antarctic Journal, 13, 32-39. DOI: $10.33275 / 1727-7485.1(17) .2018 .29$

Liashchuk, O.I.: 2014, The possibility of a tsunami warning from earthquakes Scotia Sea geophysical methods. Ukrainian Antarctic Journal, 17, 61-66. DOI: $10.33275 / 1727-7485.13 .2014 .211$

Maksymchuk, V., Bakhmutov, V., Horodyskyy, Y. and Chobotok, I.: 2009, Results and perspectives of 
tectonomagnetic investigations in the Western Antarctic. Ann. Geophys., 52, 1, 35-43. DOI: $10.4401 /$ ag-4571

Maksymchuk, V., Kuznetsova, V., Chobotok, I. and Dotsenko, I.: 2002, First results of tectonomagnetic investigation of academic Vernadsky station. Bulletin of Ukrainian Antarctic Center, 4, 197-201.

Marchenko, A., Tretyak, K., Yarema, N., Dzhuman, B. and Sidorov, I.: 2012, The field of linear velocities and movements of the Earth crust in the South-Eastern Europe region. Geodynamics, 13, 18-27. (in Ukrainian).

Mohamed, A.M.S., Radwan, A.M., Sharf, M., Hamimi, Z., Hegazy, E.E., Abou Aly, N. and Gomaa, M.: 2016, Evaluation of the deformation parameters of the northern part of Egypt using Global Navigation Satellite System (GNSS). NRIAG J. Astron. Geophys., 5, 1, 65-75. DOI: 10.1016/j.nrjag.2016.01.001

Mytrokhyn, O., Bakhmutov, V., Aleksieienko, A., Gavryliv, L. and Mytrokhina, T.: 2017, Geological position and age of Tuxen-Rasmussen layered gabbroid intrusion (West Antarctica). Ukrainian Antarctic Journal, 16, 21-28.

Mytrokhyn, O., Bakhmutov, V., Gavryliv, L. and Aleksieienko, A.: 2018, Geology of Petermann island (Wilhelm archipelago, West Antarctica). Visnyk of Taras Shevchenko National University of KyivGeology, 1, 7-15.

DOI: $10.17721 / 1728-2713.80 .01$

Pelayo, A.M. and Wiens, D.A.: 1989, Seismotectonics and relative plate motions in the Scotia Sea region. J. Geophys. Res., Solid Earth, 94, B6, 7293-7320. DOI: 10.1029/JB094iB06p07293

Richter, A., Fedorov, D.V., Fritsche, M., Popov, S.V., Lipenkov, V.Y., Ekaykin, A.A. ... and Dietrich, R.: 2013, Ice flow velocities over Vostok Subglacial Lake, East Antarctica, determined by 10 years of GNSS observations. J. Glaciol., 59, 214, 315-326. DOI: 10.3189/2013JoG12J056

Richter, A., Popov, S.V., Dietrich, R., Lukin, V.V., Fritsche, M., Lipenkov, V.Y. ...and Masolov, V.N.: 2008, Observational evidence on the stability of the hydroglaciological regime of subglacial Lake Vostok. Geophys. Res. Lett., 35, 11. DOI: 10.1029/2008GL033397

Robertson Maurice, S.D., Wiens, D.A., Shore, P.J., Vera, E. and Dorman, L.M.: 2003a, Seismicity and tectonics of the South Shetland Islands and Bransfield Strait from a regional broadband seismograph deployment. J. Geophys. Res., Solid Earth, 108, B10. DOI: 10.1029/2003JB002416

Robertson, R., Beckmann, A. and Hellmer, H.: 2003b, M2 tidal dynamics in the Ross Sea. Special Issue of Antarctic Science (Ross Sea), 15, 1, 41-46. DOI: $10.1017 / \mathrm{S} 0954102003001044$

Rosado, B., Fernández-Ros, A., Berrocoso, M., Prates, G., Gárate, J., de Gil, A. and Geyer, A.: 2019, Volcanotectonic dynamics of Deception Island (Antarctica): 27 years of GPS observations (1991-2018). J. Volcanol. Geotherm. Res., 381, 57-82. DOI: 10.1016/j.jvolgeores.2019.05.009

Rusov, V., Maksymchuk, V., Ilić, R., Pavlovych, V., Jaćimović, R., Bakhmutov, V. ... and Vaupotič, J.: 2014, The peculiarities of cross-correlation between two secondary precursors-Radon and magnetic field variations, induced by stress transfer changes. Radiat. Meas., 64, 9-22. DOI: 10.1016/j.radmeas.2014.03.011
Ryan, C.: 2007, Mesozoic to Cenozoic igneous rocks from Northwestern Graham Land: constraints on the tectonomagmatic evolution of the Antarctic Peninsula. Doctoral dissertation, University of Brighton.

Ryan, W.B., Carbotte, S.M., Coplan, J.O., O'Hara, S., Melkonian, A., Arko, R. ... and Bonczkowski, J.: 2009, Global multiresolution topography synthesis. Geochem. Geophys. Geosyst., 10, 3 . DOI: $10.1029 / 2008$ GC002332

Sagiya, T., Miyazaki, S.I. and Tada, T.: 2000, Continuous GPS array and present-day crustal deformation of Japan. Pure Appl. Geophys., 157, 11-12, 2303-2322. DOI: 10.1007/PL00022507

Sanderson, D.J. and Marchini, W.R.D.: 1984 Transpression. J. Struct. Geol., 6, 5, 449-458. DOI: $10.1016 / 0191-8141(84) 90058-0$

Savchyn, I and Pronyshyn, R.: 2020, Differentiation of recent local geodynamic and seismic processes of technogenic-loaded territories based on the example of Dnister Hydro Power Complex (Ukraine). Geod. Geodyn., 11, 5. DOI: 10.1016/j.geog.2020.06.001

Shen, Z.K., Jackson, D.D. and Ge, B.X.: 1996, Crustal deformation across and beyond the Los Angeles basin from geodetic measurements. J. Geophys. Res., Solid Earth, 101, B12, 27957-27980.

Tretyak, K. and Golubinka, Y.: 2006, Estimation and differentiation movements of a terrestrial surface in Antarctic Region. Ukrainian Antarctic Journal, 4-5, 72-83, (in Ukrainian).

Tretyak, K. and Vovk, A.: 2014, Results of determination of horizontal deformations of the Earth's crust of Europe according to the data of GNSS-observations and their relation with the tectonic structure. Geodynamics, 16, 21-33, (in Ukrainian).

Tretyak, K., Hlotov, V., Golubinka, Y. and Marusazh, K.: 2016, Complex geodetic research in Ukrainian Antarctic station "Academician Vernadsky" (years 2002-2005, 2013-2014). Reports on Geodesy and Geoinformatics, 100, 1, 149-163. DOI: $10.1515 /$ rgg-2016-0012

Tretyak, K., Romanyshyn, I. and Golubinka, Y.: 2002, To the question of determining the eccentricity of the phase center of the antenna GPS-receiver. Geodesy, Cartography and Aerial Photography, 62, 87-96, (in Ukrainian).

Vaughan, A.P. and Storey, B.C.: 2000, The eastern Palmer Land shear zone: a new terrane accretion model for the Mesozoic development of the Antarctic Peninsula. J. Geol. Soc., 157, 6, 1243-1256.

DOI: $10.1144 /$ jgs. 157.6.1243

Yegorova, T., Bakhmutov, V., Janik, T. and Grad, M.: 2011, Joint geophysical and petrological models for the lithosphere structure of the Antarctic Peninsula continental margin. Geophys. J. Int., 184, 1, 90-110. DOI: $10.1111 / \mathrm{j} .1365-246 X .2010 .04867 . \mathrm{x}$

Zanutta, A., Negusini, M., Vittuari, L., Cianfarra, P., Salvini, F., Mancini, F. ... and Capra, A.: 2017, Monitoring geodynamic activity in the Victoria Land, East Antarctica: Evidence from GNSS measurements. J. Geodyn., 110, 31-42. DOI: 10.1016/j.jog.2017.07.008

Zanutta, A., Negusini, M., Vittuari, L., Martelli, L., Cianfarra, P., Salvini, F. ... and Capra, A.: 2018, New geodetic and gravimetric maps to infer geodynamics of Antarctica with insights on Victoria Land. Remote Sens., 10, 10, 1608. DOI: $10.3390 /$ rs 10101608 